\title{
Colonoscopy practice in South Africa: The way forward
}

Over the past decades, colonoscopy has evolved from a purely diagnostic procedure to one that currently encompasses increasingly complex therapeutic interventions. The catalyst of this evolution was the adoption of screening colonoscopy for the prevention of colorectal cancer in the average-risk population. The advent of screening colonoscopies in healthy individuals also brought the need to monitor the safety and effectiveness of the procedure to the fore. In the UK, these goals are achieved through high-quality training and effective audits of the performance of trainees and practising clinicians, using direct observations of procedural skills (DOPS) assessment for the former, and key performance indicators (KPIs) for both. The main KPIs for colonoscopy are caecal intubation rate (CIR >90\%), withdrawal time (>6 minutes), quality of bowel preparation ( $>90 \%$ (adequate)) and adenoma detection rate $(\mathrm{ADR}>15 \%) \cdot{ }^{[1-3]}$ Although these parameters are assessed individually, they are interdependent.

In South Africa (SA), there are only 102 gastroenterologists and $<20$ colorectal surgeons for whom colonoscopy is a core competency. Consequently, a much smaller proportion of colonoscopies are perfomed by these specialists than in Europe and North America. The majority of colonoscopies outside the eight university gastroenterology training units are performed by general surgeons, who receive no structured training in the procedure as registrars. For example, in public hospitals in KwaZulu-Natal Province in 2016, general surgeons and surgical medical officers constituted $90 \%$ (72/89) of active endoscopists, while there were only 0.06 gastroenterologists (medical, and the surgical subspecialties) per 100000 people. ${ }^{[4]}$ In the private sector in SA, which covers a population of just $<9$ million with medical insurance, 150000 colonoscopies are performed annually, mostly by general surgeons (66\%), followed by gastroenterologists (20\%) and physicians (14\%). ${ }^{[5]}$ In contrast, only 70000 colonoscopies are performed in the $\sim 50$ million uninsured individuals who utilise state hospitals. ${ }^{[5]}$ The quality of the colonoscopy performed by the different practitioners in SA is probably highly varied and largely unknown.

In this issue of $S A M J$, two studies for the first time report information assessing the quality of colonoscopy in the public and private sectors. ${ }^{[6,7]}$ It is heartening that the CIR in both studies meets international targets. However, the proportion of examinations with adequate bowel preparation falls short of recommendations. Improving bowel preparation requires focused attention across the country, and can be improved by the use of split-dose preparations and ensuring appropriate delivery of instructions, reinforced by the use of mobile applications. These interventions should be underpinned by ongoing clinical audits, given the critical role bowel preparation plays in delivering quality colonoscopy.

Whereas the CIR measures the performance of the individual practitioner, and can be reliably used across populations, the ADR is dependent on the prevalence of colonic adenomas (colorectal cancer precursor lesions) in a population. The frequency of colorectal cancer in SA varies with ethnicity, being highest in the white and lowest in the black population. ${ }^{[8]}$ Therefore, theoretically, the target ADR in SA should vary according to the population under consideration, and it is important that this parameter be benchmarked in the various ethnic groups in the country.

At the Wits Donald Gordon Medical Centre (WDGMC), a private hospital, the average ADR was $15.6 \%$ (107/686) in a prospective audit of 1643 colonoscopies. ${ }^{[6]}$ When disaggregated by ethnicity, the ADR was $15.3 \%(83 / 543)$ in white patients, $17.6 \%(13 / 74)$ in Asians and $18.5 \%(10 / 54)$ in black patients. ${ }^{[6]}$ This study did not state whether individuals at high risk of colorectal adenomas (strong family history, adenomatous syndromes, previous colorectal cancer) were excluded, which may explain the higher than expected ADR in the black population. In contrast, the second study, from an academic state institution, Groote Schuur Hospital, Cape Town, reviewed 992 colonoscopies in people at average risk of colorectal cancer. ${ }^{[7]}$ The ADR in this study was $12 \%$ (18\% in white and Asian patients (16/103 and $2 / 13$, respectively), $13 \%(95 / 757)$ in the mixed-race population and 5\% (6/119) in black South Africans). Although these studies are hospital based, and not truly reflective of the typical healthy adult population for which ADR is regarded as the benchmark, they provide a solid basis for clinical practice in SA and the rest of Africa. From the findings, a clinician providing quality colonoscopy to a diverse population in SA should achieve a minimum ADR of $12-15 \%$, which is comparable with targets elsewhere.

There was a wide disparity in the ADR in the black population between the two studies. The ADR in the black population in the study at Groote Schuur Hospital was 5\%, and is similar to findings from elsewhere on the continent. ${ }^{[9,10]}$ The ADR in the study from WDGMC (18.5\%) was much higher, which suggests a selection bias. Worryingly, the number of black South Africans who had undergone colonoscopies in the two studies was low, possibly reflecting the underlying catchment populations of these two hospitals. Therefore, it is premature to make definitive conclusions on the prevalence of colorectal adenomas in the black population, and adequately powered population-based studies are required. Until these are available, the decision to offer a screening colonoscopy in the black population should be individualised, taking into account lifestyle and comorbid conditions, particularly diabetes mellitus, the metabolic syndrome and obesity. Diabetes mellitus was a key risk factor for colorectal cancer in the black population in a case-control study performed in Zimbabwe. ${ }^{[1]]}$

Although a formal, national population-based screening programme for colorectal neoplasia is probably not currently justifiable in SA, the well-resourced private sector serving people who have health insurance provides opportunities for structured exploratory programmes. Interestingly, the majority of the white population, who have a high incidence of colorectal cancer and are likely to derive the most benefit from screening, have health insurance coverage. A project is currently being rolled out - a faecal immunochemical test (FIT) trial - as a triage tool for average-risk patients $>50$ years of age, which will also monitor the quality of colonoscopy in those who test positive. This should also be used to generate data for future public health programmes. In the academic state sector, targeted screening and surveillance occur haphazardly for familial cancers; these require a national co-ordinated response, as does the use of FITs. A national electronic record system of endoscopic procedures can help to facilitate such data collection and standardise practice. It should include a registry for familial colorectal cancers, as systematic screening provides undoubted mortality benefits for these individuals. ${ }^{[12]}$ Expanding endoscopy registries should be a priority and will inform health policy on colonoscopy provision, screening and surveillance strategies. 


\section{Leolin Katsidzira}

Department of Medicine, College of Health Sciences, University of Zimbabwe, Harare, Zimbabwe

\section{Sandie Thomson}

Division of Medical Gastroenterology, Department of Medicine, Faculty of Health Sciences, University of Cape Town, South Africa sandie.thomson@uct.ac.za
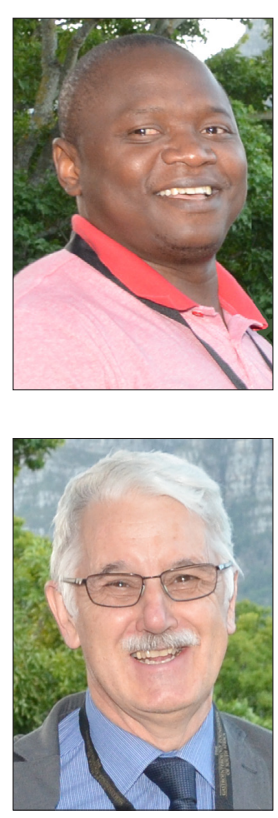

1. Rees CJ, Gibson ST, Rutter MD, et al. UK key performance indicators and quality assurance standards for colonoscopy. Gut 2016;65(12):1923. https://doi.org/10.1136/gutjinl-2016-312044
2. Rex DK, Schoenfeld PS, Cohen J, et al. Quality indicators for colonoscopy. Am J Gastroenterol 2015;110(1):72-90. https://doi.org/10.1038/ajg.2014.38

3. Rembacken B, Hassan C, Riemann JF, et al. Quality in screening colonoscopy: Position statement of the European Society of Gastrointestinal Endoscopy (ESGE). Endoscopy 2012;44(10):957-968. https:// doi.org/10.1055/s-0032-1325686

4. Loots E, Clarke DL, Newton K, Mulder CJ. Endoscopy services in KwaZulu-Natal Province, South Africa, are insufficient for the burden of disease: Is patient care compromised? S Afr Med J 2017;107(11):1022-1025. https://doi.org/10.7196/SAMJ.2017.v107i11.12484

5. Thomson SR, Katsidzira L. Quality in colonoscopy. In: Cassimjee I, ed. Proceedings of the 27th Wits Biennial Surgical Symposium: Improving Surgical Care in 2020 and Beyond. Johannesburg: Wits, 2020:143-149. https://drive.google.com/file/d/1Bf9Pupv_03PGxaryFkMYA4j9vDDFJX0o/view (accessed 27 October 2020)

6. Bouter C, Barrow P, Bizos D, et al. The 'ins and outs' of colonoscopy at Wits Donald Gordon Medical Centre, South Africa: A practice audit of the outpatient endoscopy unit. S Afr Med J 2020;110(12):1186-1190. https://doi.org/10.7196/SAMJ.2020.v110i12.14419

7. Kruger J, Katsidzira L, Setshedi M, Thomson SR. Prevalence and characteristics of incidental colorectal polyps in patients undergoing colonoscopy at a South African tertiary institution. S Afr Med J 2020;110(12):1191-1194. https://doi.org/10.7196/SAMJ.2020.v110i12.14582

8. Graham A, Adeloye D, Grant L, Theodoratou E, Campbell H. Estimating the incidence of colorectal cancer in sub-Saharan Africa: A systematic analysis. J Glob Health 2012;2(2):20404. https://doi. org/10.7189/jogh.02.020204

9. Katsidzira L, Gangaidzo IT, Mapingure MP, Matenga JA. Retrospective study of colorectal cancer in Zimbabwe: Colonoscopic and clinical correlates. World J Gastroenterol 2015;21(8):2374-2380. https:// doi.org/10.3748/wjg.v21.i8.2374

10. Alatise OI, Arigbabu AO, Agbakwuru AE, et al. Polyp prevalence at colonoscopy among Nigerians: A prospective observational study. Niger J Clin Pract 2014;17(6):756-762. https://doi. rg/10.4103/1119-3077.144391

11. Katsidzira L, Gangaidzo IT, Makunike-Mutasa R, et al. A case-control study of risk factors for colorectal cancer in an African population. Eur J Cancer Prev 2019;28(3):145-150. https://doi. $\mathrm{org} / 10.1097 / \mathrm{CEJ} J .0000000000000439$

12. Coetzee ED, Thomson SR. Inherited colorectal cancer: A plea for a national registry. S Afr J Surg 2013;51(2):42-43. https://doi.org/10.7196/sajs.1742

S Afr Med J 2020;110(12):1144-1145. https://doi.org/10.7196/SAMJ.2020. v110i12.15270 